\title{
International Security, Multiple Public Good Provisions, and The Exploitation Hypothesis*
}

\author{
May, 2012 \\ Revised November 6, 2012 \\ Toshihiro Ihori ${ }^{\mathrm{a}}$, Martin McGuire ${ }^{\mathrm{b}}$, and Shintaro Nakagawa ${ }^{\mathrm{c}}$
}

\begin{abstract}
Since the 1960's Olson-Zeckhauser's (1966) analysis, and its "exploitation of the great by the small" has provided economists' core model of alliance's provision of security/defense. But with the end of the Cold War countries allocative behavior has diverged markedly from OZ's predictions for defense as a homogeneous pure public good voluntarily provided. This paper suggests a replacement for OZ, with the essential difference that "defense" rather than being aggregated into their single public good is disaggregated into more realistic categories of self-insurance and self-protection. Because allocative behavior in public good groups is essentially driven by income effects, we concentrate on these, which become complex and conflicted, giving much greater scope for goods-inferiority. The analysis is followed by numerical simulations, which conform to actual experienced allocations in NATO much better than the conventional "exploitation" model.
\end{abstract}

Keywords: self-insurance, self-protection, inferior goods, exploitation hypothesis, multiple public goods F50, H41, H50, D81.

a: Corresponding Author, National Graduate Institute for Policy Studies, 7-22-1 Roppongi, Minato-ku, Tokyo 106-8677, Japan. phone: 03-6439-6171, fax: 03-643906010. Email: ihori@ grips.ac.jp b: Department of Economics, University of California-Irvine, Irvine, CA 92697. tel: 949-824-6190, fax: 949824-3401, Email: mcmcguir@uci.edu

c: Faculty of Economics, Shimonoseki City University; 2-1-1 Daigaku-cho, Shimonoseki, Yamaguchi 7518510, Japan; phone:+81-83-254-8655; fax:+81-83-252-8099; e-mail: s-nakagawa @ shimonoseki-cu.ac.jp.

* This paper extends parts of "National Adversity: Managing insurance and protection," presented to a Conference on "The Causes and Consequences of Conflict," Wissenschaftszentrum Berlin (WZB), Germany, March 28-29, 2008, PET conferences 2008, Seoul, Korea June 28, 2011, Indiana, USA June 4, IIPF conference 2011, Michigan, USA, August 8, 2011, and ANU, Australia, March 24, 2012. The authors thank Robin Boadway, Richard Cornes, Magnus Hoffman, Jun-ichi Itaya, Kai Konrad, Ioana Petrescu, and other conference participants for insightful comments on that earlier paper.

This is an Accepted Manuscript of an article published by Taylor \& Francis Group in Defense and Peace Economics 25:3, 213-229, on 08 Feb 2013, available online:

http://dx.doi.org/10.1080/10242694.2012.752229 


\section{INTRODUCTION}

This paper extends existing analyses of self-insurance and self-protection that countries may implement at a multi-national level in pursuit of their security. This leads us to challenge as inadequate the conventional wisdom about how separate countries in an alliance share the economic burden of defense --- the Olson Zeckhauser (OZ) model --- and to propose a better alternative as represented by our theory. This paper shows that a disaggregated self-insurance/self-protection framework can explain recent burden sharing better than the one pure public good model of Olson and Zeckhauser.

Security benefits may spill over becoming public goods among countries (Olson and Zeckhauser, 1966) which then interact in their allocations of national incomes to international (or regional) safety and welfare. Examples of these public goods include formation of international organizations, collective military preparedness, and active international diplomacy which may reduce commonly shared probabilities of regional and international tension. The distinctions of self-insurance, self-protection, and market insurance were first made by Ehrlich and Becker (1972). But application of their models to international security where market insurance for entire countries is usually unavailable remains surprisingly sparse except for some work on terrorism such as Sandler (1992, 1997, and 2005).

In particular, economists' voluntary public good (VPG) models have not been well extended to understand incentives and behaviors of sovereign agents desiring to manage risks along multiple 
channels analogous to EB's self-protection and self-insurance in a multi-good, multi-country setting. The purpose of this paper is to contribute to that extension, by explicitly investigating the effect of loss in the bad state.

With multiple types of pure public goods one should expect, allocative instability and imbalance from incentives discovered by Cornes and Itaya (2010). They demonstrated that when two agents in a partnership both could provide two different (pure) public goods, then at a Nash equilibrium, it is impossible (unless both agents have identical preference functions) for both agents to share in the provision of both goods. Here we develop a realistic formulation that can avoid that Cornes-Itaya problem in a multiple public good framework. However, instead of their problem, we face another one: goods inferiority. That is, when insurance is provided as a pure public good by/among nations in an allied group, we demonstrate a strong presumption for goods-inferiority. We show that even if the sign of income effect on self protection is positive in a single-country setting, the effect of higher income on Nash Equilibria becomes negative in a two-country setting. The cause of this anomaly we denominate as a "spillover income effect". Because of this effect corner solutions are likely to occur with respect to provision of self protection. When both self insurance and self protection are inferior, big countries should provide much less security spending than small countries, but in reality this is not normally observed. We call this seemingly paradoxical outcome the "inferiority difficulty". 
To address this difficulty, we also focus on effects of changes in loss-in-the-bad-state. If loss-in-

the-bad-state increases, it should stimulate security spending. If such loss is positively associated with income, income growth should stimulate security spending still more - a relationship that we believe will in reality better explain security allocations among allies as losses in the bad state often change over time.

Assuming CRRA utility functions, our simulations provide numerical results of income and loss-in-the-bad-state and the resulting resource allocations that support our explanatory hypothesis. We believe that these numerical examples and the theory supporting them better explain various changes in observed security spending of NATO than does the conventional wisdom.

The conventional wisdom comes from Olson and Zeckhauser (1966). Their theory led to the socalled exploitation hypothesis, whereby the large, wealthy allies shoulder the defense burdens of an entire alliance including all those of their smaller-GDP allies. If defense spending is purely public and the income effect is positive, wealthier allies can be expected to contribute more defense than less wealthy allies, provided tastes do not differ significantly among allies. Actually, some early studies of defense demand found defense to be a normal good during the Cold War, and thus, they confirmed the “exploitation hypothesis".

However, some studies have argued that the good NATO supplied was not purely public, 
especially after 1967 and were skeptical about the plausibility of the exploitation hypothesis in 1970s.

See among others Murdoch and Sandler (1984), Sandler and Forbes (1980), and Sandler and Shimuzu

(2012). As shown in Table 4.1(a), recent data on military spending after the Cold War do not support the OZ 'exploitation hypothesis.' There have been many candidates to explain why the exploitation hypothesis failed --- non Nash-Cournot allocative behavior, Lindahl behavior, systematic differences in recognition or evaluation of the "threat," inapplicability of a single utility function to represent the interests of an entire government or nation etc. Among others, Sandler and Hartley (2001) developed the joint product model. ${ }^{1}$

The argument of this paper depends on none of the foregoing "candidates." Nevertheless, from calculating the effect of changes in possible loss, our numerical examples offer an alternative explanation for historical security allocations. Specifically to explain the reduction in the security expenditures of NATO in 1990s pursuant to the fall of the Soviet Union our model show how this would follow from a decrease in NATO's threatened loss-in-the-bad-state. Thus, we present an alternative model of a defense alliance which has a richer structure, and which is more satisfactory than that of Olson/Zeckhauser (1966).

This paper consists of five sections. Section 2 formulates a basic analytical framework for two allied countries, and derives the optimization conditions. In Section 3, investigating the income effects 
on self-insurance and self-protection, the analysis explores how in a two country world an increase in the income of one country affects its self-insurance and self-protection through the response of the other country. Section 4 presents some numerical results to illustrate security allocations and evaluate the plausibility of exploitation hypothesis. Here we show how our insurance/protection framework implies behavior close to observed NATO allocations. Finally section 5 concludes.

\section{ANALYTICAL FRAMEWORK}

\subsection{Basic assumptions}

Suppose that the world consists of two countries: A and B. We consider two contingent states of the world: a good state "1" and a bad state, "0". Ignoring all insurance and compensation possibilities expected utility for country $i(i=A, B)$ is given as:

$$
W^{i}=p U^{1}\left(C^{1 i}\right)+(1 \quad p) U^{0}\left(C^{0 i}\right),
$$

where $W^{i}$ is country $i$ 's expected utility, $C^{l i}$ is $i$ 's consumption in a good state, $C^{O i}$ is $i$ 's consumption in a bad state, and $p$ is the chance of a good state. Although we consider the term "1-p" as the risk of invasion or war, it might be the risk of trade interruption, disease outbreak, or natural disaster. Utility function $\mathrm{U}\left(\right.$ ) is assumed to be the same whether luck is good or bad. $U^{1}$ denotes realized utility if the good event happens, and $U^{0}$ if the bad event happens, and $U_{Y} \quad U / Y>0, U_{Y Y} \quad{ }^{2} U / Y^{2}<0$. 
We will focus on the two canonical types of Ehrlich-Becker (EB) defense; (i) EB's "selfprotection;" which raises the chance of a good state, (ii) EB's "self-insurance" which reduces the loss in a bad state. Countries can provide self-insurance and self-protection mutually, as public goods for each other. The individual country's budget constraint is given as

$$
C^{1 i}=Y^{i} \quad m_{1}^{i} \quad m_{2}^{i} ; C^{0 i}=Y^{i} \quad m_{1}^{i} \quad L^{i},
$$

where $Y^{i}$ is the fixed national income of country $i, m_{1}^{i}$ represents country $i$ 's allocation to risk improving self-protection, $\quad m_{2}^{i}$ gives the expenditure on self-insurance in good times (measured in units of $\left.\mathrm{C}^{1 \mathrm{i}}\right), m_{2}^{i}$ represents the amount of self-insurance purchased by country $i$ at price $\quad$, and $L^{i}$ gives the loss for country $i$ in a bad state.

The first risk management instrument to consider is self-protection. Both $m_{1}^{A}$ and $m_{1}^{B}$ spent on self-protection decrease the chance of a bad event, 1-p, from what we call "baseline risk ${ }^{2}$ of [1-p(0)]."

Thus we use the collective summation technology by writing

$$
p=p\left(M_{1}\right)
$$

where $M_{1}$ is the sum of the self-protection of the two countries

$$
M_{1}=m_{1}^{A}+m_{1}^{B}
$$

Here, we assume that $p^{\prime}>0$ and $p^{\prime \prime}<0$ throughout. $M_{1}$ is an international public good.

The second risk management instrument is self-insurance. The loss for country $i$ in the bad state is 
given as

$$
L^{i}=\bar{L}^{i} \quad F\left(M_{2}\right)
$$

where $\bar{L}^{i}$ is the baseline loss for country $i$ in that bad state, $F\left(M_{2}\right)$ is the self-insurance benefit, and

$M_{2}$ is the sum of the self-insurance outlays. $M_{2}$ is also an international public good.

$$
M_{2}=m_{2}^{A}+m_{2}^{B}
$$

Self-insurance differs from standard market insurance in that self-insurance benefit function $F\left(M_{2}\right)$ should show diminishing returns or increasing costs. $1>F^{\prime}>0, F^{\prime \prime} \leq 0$. EB make this assumption also, and refer glancingly to the role of human capital in providing for self-insurance as a source of diminishing returns. National self-insurance may often involve actions like stockpiling or standby production maintenance and these surely will show diminishing returns ${ }^{3}$. Declining "productivity" of $" \mathrm{M}_{2} "$ thus is the first source of a distinction between sovereign self-insurance vs. lesser scale decentralized market insurance.

A second major difference between self-insurance as provided by an entire country and ordinary market insurance is that when a whole nation provides insurance to itself, fair pricing would seem to be the standard case and not an outlier just referenced for comparison. Moreover, it is plausible to assume that the nation as a price maker, not as a price taker, incorporates this actuarially fair condition in its optimization. 


\subsection{Optimization of each country}

In our formulation of a two country model the expected utility may be rewritten as

$$
W=p\left(M_{1}\right) U^{1}\left[Y-m_{1}-\frac{1-p\left(M_{1}\right)}{p\left(M_{1}\right)} m_{2}\right]+\left(1-p\left(M_{1}\right)\right) U^{0}\left[Y-m_{1}-\left\{\bar{L}-F\left(M_{2}\right)\right\}\right]
$$

Expected utility (1)' is maximized with respect to $m_{1}^{i}$ and $m_{2}^{i}$ subject to (2), (3), (4), (5), and (6)

for each country. This gives (7) as the first order condition (FOC) for self-insurance, and (8) as the FOC

for self-protection.

$$
\begin{gathered}
F O C_{\left\{M_{2}, C^{i}\right\}}:-p \pi U_{Y}^{1 i}+(1-p) U_{Y}^{0 i} F^{\prime}\left(M_{2}\right)=0 \\
F O C_{\left\{M_{1}, C^{i}\right\}}:\left[p^{\prime}\left(U^{1 i}-U^{0 i}\right)\right]-\left[p U_{Y}^{1 i}+(1-p) U_{Y}^{0 i}\right]-\left[\left(\frac{d \pi}{d M_{2}}\right) m_{2}^{i} U_{Y}^{1 i}\right]=0 .
\end{gathered}
$$

To begin with, we consider the FOC for self-insurance. Eq. (7) shows the expected marginal

utility cost of providing $m_{2}$ i.e. $\left[\begin{array}{ll}p & U_{Y}^{1 i}\end{array}\right]$, equal to the expected marginal utility benefit of providing $m_{2}$,

i.e. $(1 \quad p) U_{Y}^{0 i} F^{\prime}$, evaluated at the solution value of $\mathbf{M}_{2}$. If this necessary condition is rewritten as in (9)

then its actuarial meaning becomes clear. The RHS there gives the probability weighted marginal insurance/benefit receipt under adversity for the last, probability-weighted dollar of premium paid in good times

$$
U_{Y}^{1} / U_{Y}^{0}=[(1-p) / p \pi] F^{\prime}\left(M_{2}\right)
$$

If self-insurance is actuarially fair (henceforth simply "fair") as we believe should be the paradigm 
for an entire country then the concept must be defined as in eq. (10).

$$
=\left(\begin{array}{ll}
1 & p
\end{array}\right) / p
$$

Inserting eq. (10) into (7), then the optimum simplifies to

$$
U_{Y}^{1 i} / U_{Y}^{0 i}=F^{\prime}\left(M_{2}\right)
$$

In contrast to the linear market insurance case no equivalence is implied between $U_{Y}^{1 i}$ and $U_{Y}^{0 i}$, with significant implications, we shall see for the inferiority vs. normality of insurance.

Next we investigate the FOC for self-protection (8). Inserting the condition for actuarial fairness

(10) directly gives:

$$
\left[p^{\prime}\left(U^{1 i}-U^{0 i}\right)\right]-\left[p U_{Y}^{1 i}+(1-p) U_{Y}^{0 i}\right]+\left[\left(p^{\prime} / p\right) m_{2} U_{Y}^{1 i}\right]=0 .
$$

We can characterize this optimality condition on the provision of self protection saying that there are

"direct" marginal benefits in the form of the gain in utility $\mathrm{p}^{\prime}\left(\mathrm{U}^{1 \mathrm{i}}-\mathrm{U}^{0 \mathrm{i}}\right)$, "direct" marginal costs $\left[\mathrm{pU}^{1 \mathrm{li}} \mathrm{Y}\right.$ $\left.+(1-\mathrm{p}) \mathrm{U}^{0 \mathrm{i}} \mathrm{Y}\right]$ and "indirect" benefits, $p^{\prime} m_{2} U_{Y}^{1 i} / p$, comprised of, an unambiguous gain from the decrease in insurance premiums paid for the same $\mathrm{m}_{2}$ coverage received. These indirect benefits stem from the lower price implied by lower risk (1-p).

\subsection{Cornes-Itaya problem}

If we consider multi-types of pure public goods, a source of instability and imbalance may 
follow from incentives discovered by Cornes and Itaya (2010). They demonstrate that when two agents in a partnership or alliance both could provide two different (pure) public goods, then at a Nash equilibrium, it is impossible (unless both agents have identical preference functions) for both agents to share in the provision of both goods at an interior solution. On the other hand, if countries are identical, the problem --- and the amount of each good supplied by each country --- becomes indeterminate. This is the Cornes-Itaya problem. If the Cornes-Itaya formulation is extended to allow variable costs associated with public good provision, this immediately eliminates the indeterminacy associated with interior equilibria.

Observe that unlike the standard constant-average-cost formulation (conventional in the voluntary public good model of groups, including Cornes-Itaya) in our formulation of a two country

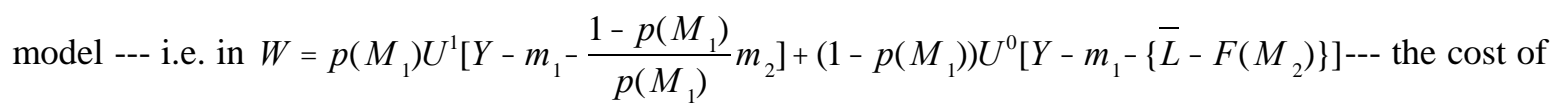
insurance is a non-linear function of $m_{1}, m_{2}$. And this non-linear "technology" for transforming $C^{1 A}$ into $M_{1}, M_{2}$ using $m_{1}^{A}, m_{2}^{A}$ for country A (same for country B with superscript "B), implies that $m_{2}^{A}$ appears in the first order condition (12) along with $C^{1 A}, M_{1}, M_{2}$, so that we may determine $m_{1}^{i}, m_{2}^{i}(\mathrm{i}=\mathrm{A}, \mathrm{B})$ in a two-pure-public-good model. That is, we can have an interior solution for both types of pure public goods even if both countries are not identical. The present formulation, suggested by the alliance application, is a specific example which inherently has variable costs and thereby removes 
indeterminacy.

\section{INCOME EFFECTS ON PUBLIC GOODS}

\subsection{Income effects ignoring the spillover effect from the other country}

We first investigate the inferiority vs. normality of self-insurance in a one country setting where

the spillover effect from the other country is ignored. Total differentiation of FOC (7) gives:

$$
\left.m_{2}^{i} / \quad Y \quad M_{Y}=\left[\begin{array}{llll}
p & U_{Y Y}^{1 i} & (1 & p
\end{array}\right) U_{Y Y}^{0 i} F^{\prime}\right] / D,
$$

where D represents the second order condition (SOC).

$$
S O C_{\left\{M_{2}, C^{i}\right\}}: D=p \pi U_{Y Y}^{1 i}-(1-p) F^{\prime} U_{Y Y}^{0 i}+(1-p) U_{Y}^{0 i} F^{\prime \prime}<0 .
$$

From the SOC we know therefore

$$
p U_{Y Y}^{1 i}(1 \quad p) U_{Y Y}^{0 i} F^{\prime}<\left(\begin{array}{ll}
1 & p
\end{array}\right) U_{Y}^{0 i} F^{\prime \prime} \text { and }-(1-p) U_{Y}^{0 i} F^{\prime \prime} \geq 0 \text {. }
$$

Hence the sign of the numerator in Eq. (13) is ambiguous and $\mathrm{m}_{2}$ as self-insurance may be inferior depending on the pricing of insurance.

Specifically, if the numerator is positive, given the SOC, the sign of Eq. (13) is negative, and $\mathrm{m}_{2}$ becomes inferior ${ }^{4}$. Absolute risk aversion $\mathrm{R}$ is defined as

$$
R=U_{Y Y} / U_{Y} \text { or }-U_{Y Y}=R U_{Y}
$$

If risk aversion is increasing $\left(R_{1}>R_{0}\right)$, then $\mathrm{D}<0$, and hence the sign of (13) is positive. On the other 
hand, the sign of (13) becomes negative if risk aversion is decreasing. Thus, if risk aversion is increasing (decreasing), $\mathrm{m}_{2}$ is normal (inferior). And if relative risk aversion is constant, absolute risk aversion will be decreasing and hence $m_{2}$ becomes inferior. Self insurance will prove inferior even if it is fairly priced and optimally provided since even optimal and fair self-insurance will not in general equalize incomes or marginal utilities across contingencies. The differential in incomes across contingencies is attributable to the declining productivity of self-insurance, as shown in (11), which contrasts with the complete coverage and equalization of incomes that results from fairly priced and optimally provided market insurance. Thus, the dilemmas implicit in goods-inferiority as they apply to group allocation become more salient and serious when a group is composed of "self-insurers".

As to the income effect on self-protection, the possibility that it is a normal good cannot be completely excluded simply by assuming that absolute risk aversion decreases with wealth. Taking total differentiation of FOC (8) gives:

$$
\frac{\partial m_{1}}{\partial Y}=-\frac{p^{\prime}\left(U_{Y}^{1}-U_{Y}^{0}\right)-\left[p U_{Y Y}^{1}+(1-p) U_{Y Y}^{0}\right]+U_{Y Y}^{1} p^{\prime} \frac{m_{2}}{p}}{E}
$$

where E represents the second order condition (SOC).

$$
\begin{aligned}
E=p^{\prime \prime}( & \left.U^{1}-U^{0}\right)-2 p^{\prime}\left(U_{Y}^{1}-U_{Y}^{0}\right)+\left[p U_{Y Y}^{1}+(1-p) U_{Y Y}^{0}\right] \\
& -U_{Y Y}^{1} \frac{p^{\prime} m_{2}}{p}\left(-1+\frac{m_{2} p^{\prime}}{p^{2}}\right)+U_{Y}^{1} \frac{m_{2}}{p^{2}}\left(p p^{\prime \prime}-p^{\prime} p^{\prime}\right)<0 .
\end{aligned}
$$

Unlike self insurance, we cannot completely exclude the possibility of a normal case simply by 
assuming that absolute risk aversion decreases with wealth. Here if absolute risk aversion is increasing/decreasing and (1-p) is initially low/high, $\mathrm{m}_{1}$ will be normal, while if absolute risk aversion is decreasing/increasing and (1-p) is low/high, $\mathrm{m}_{1}$ becomes inferior.

\subsection{Spillover income effect in a two country model}

So far we have ignored spillover effects from the other country. Ihori, McGuire, and Nakagawa (2011) investigate income effects in a two country framework general equilibrium. Those analytical results become complicated and ambiguous. Thus, in order to explain recent burden sharing within NATO in this paper we present further analysis of these phenomena by means of examples/simulations.

Nevertheless, the analysis we believe is quite general.

We begin with an intuitive explanation of the spillover-income effect from the partner country.

Suppose self-protection $\mathrm{m}_{1}$ is normal but self-insurance $\mathrm{m}_{2}$ is inferior for each country considered separately. Then if country A's wealth rises (or economic growth occurs), we would expect $m_{1}^{A}$ to increase, and $m_{2}^{A}$ to decline. However, in a two-country model, we need to consider response of the other

country B. Now, a decline in $m_{2}^{A}$ stimulates country B's provision of $m_{2}^{B}$, which then stimulates $m_{1}^{A}$.

The intuition is as follows: when one country A (home) reduces its provision of security $m_{2}^{A}$ it creates a negative externality for its partner country B (foreign), and hence the partner's effective (or 
full) income $Y^{B}+m_{1}^{A}+m_{2}^{A}$ declines. But when the public good is inferior, the partner will react to a decrease in its full income by increasing its provision of that public good $m_{2}^{B}$. This generates a positive externality for home A by reducing the marginal benefit of raising $m_{2}^{A}$, which then will react by reducing its provision $m_{2}^{A}$ further. Now, this will reduce both the marginal benefit of raising $m_{1}^{A}$ and the marginal cost of raising $m_{1}^{A}$ since consumption in the bad state has become higher due to the increase in $m_{2}^{B}$. If the former effect is larger than the latter effect, $m_{1}^{A}$ declines. Hence, if its income rises country A may reduce $m_{1}^{A}$ in the two-country framework even if $m_{1}^{A}$ is normal in a one country setting.

Schematically:

$$
\begin{aligned}
\Delta Y^{A}>0 \Rightarrow \begin{array}{r}
\Delta m_{1}^{A}>0 \\
\Delta m_{2}^{A}<0
\end{array} & \Rightarrow \Delta\left(Y^{B}+m_{1}^{A}+\pi m_{2}^{A}\right)<0
\end{aligned} \quad \begin{gathered}
\Delta m_{2}^{B}>0
\end{gathered} \Rightarrow \Delta m_{1}^{A}<0 \text { if the decline of marginal benefit is large }
$$

We call this negative spillover effect "the spillover income effect". Thus, there could be a corner Nash equilibrium at which only one of the two countries, (here country B), provides the public good of selfprotection than it would absent an alliance partner in a one country model. Our simulation result in Appendix confirms this conjecture.

When each country can provide both types of public good ${ }^{5}$, as explained above both types of security can become inferior if absolute risk aversion declines with wealth. And as recognized, for example, in Kerschbamer and Puppe (1998) or in Ihori and McGuire (2007, 2010), when a public good 
is inferior, the Nash equilibrium solution for two countries easily becomes unstable implying a corner solution where only one country provides the public good. However actual data on military spending do not seem to support such inferiority. We call this seemingly paradoxical outcome the inferiority difficulty.

\subsection{Changes in Loss in the Bad State}

Now if loss-in-the-bad-state increases, it raises security spending, and if the loss is positively associated with income, then income growth would also likely raise security spending. Thus, if we include changes in both income and loss-in-the-bad-state, we should have a better, more realistic, explanation of security spending among allies.

First of all, an increase in $\bar{L}$ itself would raise the demand for self-insurance. It is easy to show

that

$$
\frac{\partial m_{2}}{\partial \bar{L}}=\frac{(1-p) U_{Y Y}^{0} F^{\prime}}{D}>0
$$

Second, if $\bar{L}$ increases with national income $(\bar{L}=Y)$, it could happen that the overall income effect from both changes in $\bar{L}$ and $\mathrm{Y}$ combined may become positive even though $\mathrm{m}_{2}$ is an inferior good.

$$
\frac{\partial m_{2}}{\partial Y}=\frac{p \pi U_{Y Y}^{1}-(1-\alpha)(1-p) U_{Y Y}^{0} F^{\prime}}{D}=\frac{p \pi U_{Y Y}^{1}}{D}+\frac{-(1-\alpha)(1-p) U_{Y Y}^{0} F^{\prime}}{D} .
$$

The first term on the RHS of Eq.(18) represents the effect of income on the provision of self-insurance, 
which is positive since $\mathrm{D}<0$. The second term on the RHS denotes the effect of income change upon the associated loss-in-the-bad-state --- which in turn changes the provision of self-insurance, and is negative.

Here if is high, the second term on the RHS of Eq.(18) becomes small. This means that the effect of increasing income on the marginal provision of $\mathrm{m}_{2}$ is cancelled and reversed by the effect of increasing loss. Thus, increasing income with its associated loss may raise self-insurance, overwhelming the negative income effect.

\section{NUMERICAL RESULTS ${ }^{6}$}

(TABLE 4.1)

\subsection{Exploitation hypothesis and burden sharing in NATO}

Olson (1965) and Olson and Zeckhauser (1966) pointed out the so-called exploitation hypothesis, whereby large wealthy allies shoulder the defense burdens of smaller allies. Olson and Zeckhauser confirmed their 'exploitation hypothesis' based on 1964 defense budgets. If the income effect is positive, we may theoretically confirm the 'exploitation hypothesis'. Indeed, Oneal and Diehl (1994) --- using pooled regression analysis for 1950-1986 --- argued that Olson's original emphasis on the public nature of the good supplied by the alliance was valid. But while the OZ hypothesis seems to 
have support in earlier periods of the Cold War, recent changes in military spending do not seem to comport with the "exploitation hypothesis."

Murdoch and Sandler pointed out that between United States (US) and western European countries the difference in military expenditure-as-a-ratio-of-GDP decreased from 1960 to 1979 (Murdoch and Sandler 1984, p.84). Tables 4.1 (a) and (b) respectively show 5-year average military expenditures and national GDP's of 14 countries that were members of NATO during 1975-2009 (excluding Iceland). In the second half of 1970s, the proportionate military expenditure of the US is not significantly large compared to smaller countries, e.g. in 1975-1979 the military expenditure of the US was $5.0 \%$, while that of Germany was $3.4 \%$ of GDP. In 1980s, the US increased its proportionate military expenditure, while smaller countries decreased theirs. In 1990s with the end of Cold War, most of the countries in the NATO decreased their military expenditures. The magnitude of decline was largest for the US and less so in the smaller countries. Thus, for the US average military expenditure as a percentage of GDP declined between 1985-1989 and 1990-1994 by 1.4\% while for the smaller countries the decline was somewhat less i.e. 1\%. During this period of time, the US GDP as a share of all-NATO GDP increased from $52.7 \%$ to $52.8 \%$. In absolute terms the decrease in the security outlay of US was significantly large. Presently we will use our framework to explain the structure of these changes in NATO burden sharing. 
There have been many candidates to explain why the OZ hypothesis failed both after and even during the Cold War --- non Nash-Cournot behavior, Lindahl behavior, systematic differences in recognition or evaluation of the "threat," inapplicability of a single utility function to represent the interests of an entire government or nation etc. Some studies have argued that the NATO-supplied-good was not purely public, especially after 1967. See, for instance, Sandler and Hartley $(1995,2001)$. These authors were skeptical about the plausibility of the exploitation hypothesis in 1970s. They developed a joint product model, as an important extension of the pure public good model. The theoretical analysis of a joint product model is provided by Cornes and Sandler $(1984,1994)$. They provide comparative statics of the joint product model including the income effects, and show, among others, that the complementarity/substitutability between the private and public benefits of security expenditure affects not only the magnitude of the income effect but also the sign of that effect.

Our theoretical framework differs from those joint production models in several respects. First, defense good inferiority is far more plausible and likely to occur in our model. In the joint product model, contribution to the public good is inferior if the private and the public benefits of the contribution are strong complements (Cornes and Sandler 1994). In our model, defense good inferiority results from decreasing absolute risk aversion. Second, we formalize the uncertainty of the bad event following the state-of-the-world approach. The effects of risk aversion and of loss in the bad state on contribution to 
alliance security can be explicitly investigated in our model. As we show below these factors help to explain recent burden sharing in NATO. Thus, our model is complementary with the joint product model, rather than a substitute. Our theory developed above, does conform with the history of NATO burden sharing as in Olson and Zeckhauser during the Cold War. But at the same time, we also explain the failure of Olson and Zeckhauser after the Cold War.

\subsection{Specification for simulations}

To highlight several changes in observed security spending in NATO, we report numerical simulations of the impact of changes in income and possible loss. We specify the form of utility with the constant relative risk aversion (CRRA) function:

$$
U(C)=\frac{C^{1}}{(1 \quad)}
$$

where $(>0)$ is the measure of constant relative risk aversion. This function implies that absolute risk aversion is decreasing with consumption. As shown in section 3, with CRRA utility the sign of income effect on self-insurance, therefore, is negative.

We also specify the risk reduction function as ${ }^{7}$

$$
p\left(M_{1}\right)=\frac{p_{d} M_{1}+1}{p_{d} M_{1}+\left(1 / p_{0}\right)} .
$$

In equation (20), $p_{0}$ is the baseline probability of the good state when no expenditure is made on self- 
protection, and $p_{d}$ is a parameter for the marginal risk reduction from an increment of expenditure. This

marginal risk reduction is given by

$$
\frac{d p}{d M_{1}}=\frac{p_{d}}{\left(p_{d} M_{1}+\left(1 / p_{0}\right)\right)^{2}}\left(\frac{1}{p_{0}} 1\right)
$$

which is positive but decreasing with $\mathrm{M}_{1}$. Unlike Tullock's (1967) and Hirshleifer's (1989) contest success functions, equation (20) assumes that self protection is a pure public good and hence the sum of the outlays by allies determines the risk of the bad state. Using this functional form, the risk reduction function has the following properties:

$$
p_{0} \leq p\left(M_{1}\right)<1 \text { and } p^{\prime}\left(M_{1}\right)>0 \text { for any } M_{1} \geq 0 \text {, and } \lim _{M_{1} \rightarrow \infty} p\left(M_{1}\right)=1 \text {. }
$$

Note that there is no upper bound to the expenditure on self-protection.

For simplicity, we specify the loss reduction function as a linear function of the sum of expenditures by the two allied countries:

$$
F\left(M_{2}\right)=M_{2},
$$

where is the degree of loss reduction from one unit of expenditure. Then $1>F^{\prime}=, F^{\prime \prime}=0$.

(TABLE 4.2)

Table 4.2 gives the values of parameters chosen for the simulation. For the parameter settings, in 
a one country framework the income effect on self-insurance is negative, but the effect on self-protection is positive.

(TABLE 4.3)

\subsection{Numerical simulation of a scenario similar to NATO's history}

Table 4.3 now shows --- in a compressed style --- elements of a scenario with GDP and defense outlay changes similar to NATO's history and thus related to the history of changes in burden sharing within NATO. We considered a bi-nation, asymmetric configuration where country B's income is $60 \%$ of A's, and the potential loss of B is also $60 \%$ of that of A. This reflects the data shown in Table 4.1; in 1985-1989 the sum of the second to fourth largest GDPs (Germany, UK, and France) is 53\% of US GDP, and the sum of the second to fifth GDPs (adding Italy) is 67\% of the US.

In 1970s, many empirical studies suggest that compared with small countries the big country (US) reduced its security spending, which is inconsistent with the Olson-Zeckhauser exploitation hypothesis. Here we explain this as a move from column 1 to column 2 in Table 4.2. This move follows from an increase in income while loss in the bad state remained fixed. Row 19 shows that country A 
reduces its security spending/GDP due to the negative income effects. On the other hand, in 1980s the big country raised its security spending by a lot --- which is consistent with the exploitation hypothesis. This could be reflected as a move from column 2 to column 3. This move includes both an increase in income and an increase in loss in the bad state. A decline in loss reduces the expenditures of a big country on self-insurance and self-protection more than those of small country. Yet within the parameters (Table 4.2) of this simulation, raising both the loss and together with it the income of one country produces minimal effects on welfare in Nash-optimized equilibrium. Still this outcome benefits both the richer "partner" (country A) (despite its higher loss), and the poorer partner (country B) as well. The correlated increase in loss in country A with the increase in income raises its security outlay and generates positive spill-overs into country B. This move from Col 2 to 3 reflects the increase in loss from the rising threat posed by the Soviet Union of the 1980's.

As shown by the move from column 3 to column 4, we examined a reduction of loss in both countries, with income remaining fixed; and found that the decline in loss reduced expenditures of country A on both self-insurance and self-protection more than those of country B --- results that directly conflict with the exploitation hypothesis. After the Cold War in 1990s the big country reduced security spending more than small countries. Here we may suppose that there was a decline in loss for the bad state while income remained fixed. It seems reasonable to conjecture that the fall of the Soviet Union 
reduced the loss in the bad state and caused a reduction in security outlays in the NATO countries ${ }^{8}$.

Note that the reduction in self-protection by the big country, decreases the probability of the

good state, p, and raises the probability of the bad state, 1-p. Row 9 in Table 4.3 also shows how a decrease in loss in the bad state leads to an increase in its likelihood. After 9/11 in the 2000's, the US raised its security spending substantially. This change corresponds to a reverse move from column 4 to column 3 in Table 4.3, i.e. an increase in loss in the bad state with income remaining fixed.

Thus, our approach where defense is disaggregated into two components, insurance and protection, potentially dominates the single public good OZ model. Our new models of burden sharing and the numerical examples used to illustrate them can explain these developments in security spending in the real world, and do it better than the traditional OZ model. Since our approach produces a variety of cases including multiple equilibria and corner solutions, it could plausibly explain recent changes in actual security spending as well. ${ }^{9}$.

\section{CONCLUSION}

This paper has investigated two types of security spending available to expected utility maximizing agents faced with "costs of emergency", namely self-insurance and self-protection. We applied a model of self-insurance and self-protection to groups of two countries where such insurance 
and protection are public goods. We demonstrated that since self-insurance is likely to be inferior, self protection can also become inferior and hence an inherent potential exists --- due to a spillover income effect --- for destabilizing incentives to generate corner outcomes in the provision of these public goods. Specifically, we showed that even if the sign of the income effect on self-protection is normal in a onecountry model, it may become negative in a two-country setting due to the spillover income effect, and hence with respect to self-protection corner solutions are more likely. When both self insurance and self protection become inferior, the big country should provide less security spending than the small country, (though this has not been observed yet or recorded). We call this seemingly paradoxical outcome the "inferiority difficulty". To solve it, we considered changes in loss-in-the-bad-state and showed how this problem can be avoided. Theoretically, if loss in the bad state increases, it stimulates security spending. Thus, if we consider changes in both income and loss in the bad state, we can offer a better and more realistic explanation of security spending of countries in an alliance.

Next, assuming CRRA utility functions, we reported simulation results of effects of a smaller loss or greater national income upon Nash equilibria allocations. We showed that the big country A's optimal self-insurance and self-protection increase when both loss in the bad state and income also rise.

We presented a range of hypothetical scenarios to depict recent developments of burden sharing in NATO. Recent data on military expenditures suggested that the exploitation hypothesis may not be 
relevant to the post Cold War era. No longer is the "exploitation of the great by the small" so crucial as in the early days of NATO. It seems reasonable to conjecture that the fall of the Soviet Union reduced the loss in the bad state and caused the reduction in security outlays in the countries of NATO. We may well explain these changes in security spending.

Although true that a 2-player formulation is limited, we conjecture that our model captures the essence of multiplayer games. Moreover, the analysis rests on the summation (linear) technology applying to both self-protection and self-insurance; and there are many other technologies including weakest-link or threshold that could apply to these questions and provide different outcomes. Extending all these limitations should be left for future research.

We do not insist that our explanation is the only one to deal with the observed expiration of OZ's exploitation hypothesis. The joint product model and other factors could explain its decline. But overall, our approach where defense is disaggregated into two components, insurance and protection, potentially dominates the single public good OZ model. Our simulations and a variety of cases of resource allocations implied by our theory --- including negative income effects --- could account for a good share of the recent changes in security spending. It is hoped that this paper may have highlighted the importance of issues of multiple public goods, instabilities, corner solutions, and conflicts of manypartner alliances in providing national security. 


\section{APPENDIX: Some Simulation Results}

We first conducted numerical simulations in which country A's income increases from 40 to 80 ,

while country B's income remains unchanged at 40 . The result of this simulation is presented in Table

A.1. When $Y^{A}=Y^{B}=40$, there are multiple Nash equilibria, shown in column 1 to column 3 . After country A's income exceeds 40, there is a unique Nash equilibrium in which A contributes nothing to self-protection.

The impact of A's economic growth decreases A's security expenditure on self insurance, but increases B's expenditure on self insurance. Row 6 shows the self-insurance of country A, and row 8 shows that of B. Comparing column 2 with column 4, A's self-insurance decreases with its income growth, while B's self-insurance increases when A's income rises. The increase in A's income reduces A's self-insurance, which, in turn, reduces B's full income and increases B's self-insurance since $m_{2}^{B}$ is inferior. The increase in A's income also increases B's self-protection and finally it, therefore, reduces A's self protection. Thus, self protection becomes inferior in a two country setting. This is due to the spillover income effect, (of A upon B) explained in section 3.2. Because the decline in $\mathrm{m}_{2}{ }^{\mathrm{A}}$ reduces B's full income, the increase in B's self-insurance that follows reduces A's marginal benefit of self-protection.

Row 15 and row 16 show the welfare impact of A's income growth. Country A's growth 
improves the welfare of country A, but reduces that of B. In a sense, therefore, we have an 'inverse' exploitation hypothesis, that is, "exploitation of the small by the great" --- just the opposite of Olson and Zeckhauser. In other words, when the income effect becomes negative, the standard exploitation hypothesis does not hold.

Next, Table A.2 shows results of a simulation where country A's loss in the bad state and its income increase parametrically $(\alpha=0.5)$ while B's loss and income remain constant. Unlike Table A.1, Table A.2 shows that at Nash equilibrium (after changes in both income and possible loss) country A's optimal self-insurance as well as its self protection increase.

To investigate another effect --- specifically of changes in possible loss --- with income fixed in an asymmetric economy, we conducted the numerical simulation of Table A.3. There we consider an asymmetric configuration where country B's income is $60 \%$ of A's income, and the loss for B is also $60 \%$ of that of A. We reduce $\bar{L}^{A}\left(\bar{L}^{B}\right)$ from 21(12.6) to 7(4.2). This decline in loss reduces the expenditure of rich-country A on both self-insurance and self-protection. Comparing column 7 and column 3, we find that a decrease in $\bar{L}^{B}$ from 6.6 to 4.2 reduces $m_{2}^{B}$. However, comparing column 3 to column 1, a decrease in loss from 12.6 to 6.6 raises B's self-insurance (from 0.0 to 0.422 ) --- which seems paradoxical. The direct effect of a decrease in loss, as explained above, is to reduce insurance. However, we also have an indirect effect: a decrease in security spending by A reduces the positive 
spillover into country B. Since $m_{2}^{B}$ is inferior, this decline in positive spillover raises $m_{2}^{B}$. When A is large and B is small, the spillover income effect from country A may dominate the direct effect, leading to the paradoxical increase in $m_{2}^{B}$.

\footnotetext{
* This paper extends parts of "National Adversity: Managing insurance and protection," presented to a Conference on "The Causes and Consequences of Conflict," Wissenschaftszentrum Berlin (WZB), Germany, March 28-29, 2008, PET conferences 2008, Seoul, Korea June 28, 2011, Indiana, USA June 4, IIPF conference 2011, Michigan, USA, August 8, 2011, and ANU, Australia, March 24, 2012. The authors thank Robin Boadway, Richard Cornes, Magnus Hoffman, Jun-ichi Itaya, Kai Konrad, Ioana Petrescu, and other conference participants for insightful comments on that earlier paper. The authors wish to acknowledge the helpful comments of the editor and two anonymous referees. If there should be any errors these remain the sole responsibility of the authors.
}

${ }^{1}$ On the other hand, Oneal and Diehl (1994) argued that Olson's original emphasis on the public nature of the good supplied by the alliance remains valid using pooled regression analysis for 1950-1986.

${ }^{2}$ Our "baseline risk" corresponds to what is sometimes referred to as "background risk" in economics of insurance analyses. Background risk distinguishes "independent" background risk where $p(0)$ is not influenced by the value of $\mathrm{L}(0)$ as in our model here, versus "non-independent" background risk where $\mathrm{p}(0)$ and $\mathrm{L}(0)$ are interdependent, and asks how the choice of protection or insurance varies with the independence property (See Schlesinger, 2000).

${ }^{3}$ In an example of flood protection and insurance, as greater quantities of consumables are set aside during dry years, their costs of preservation and delivery during good years might increase more than proportionately. ${ }^{4}$ Note if self-insurance is fair and therefore $(1-p)=p \pi$, then the numerator of $(13)$ becomes $p\left(U^{1} Y_{Y}-U^{0} Y Y\right)$. ${ }^{5}$ Our simple solution to the problem of diminishing returns and distribution of infra marginal costs/gains in a public good spillover environment will be to assume a "summation finance aggregator," $\mathrm{M}=\sum \mathrm{m}$, in the provision of public good, even though $\mathrm{p}(\mathrm{M})$, represents a "non-summation consumption aggregator" (e.g. $\left.\mathrm{p}(\mathrm{M}) \neq \sum \mathrm{p}_{\mathrm{i}}\left(\mathrm{m}_{\mathrm{i}}\right)\right)$ Then, importing an idea from contest theory we take primitive preferences as being over contributions to insurance or to risk reduction, rather than insurance coverage or risk reduction itself.

${ }^{6}$ To conduct the numerical simulations, we used Mathematica 7.0.0.

${ }^{7} \mathrm{Eq}(20)$ can be rewritten as $p\left(M_{1}\right)=p_{0}+\left(\begin{array}{ll}1 & p_{0}\end{array}\right)\left[\frac{M_{1}}{M_{1}+\left(1 / p_{0} p_{d}\right)}\right]$. The RHS can be interpreted as a convex combination of unity and a Tullock's contest success function where the weight of the former is $p_{0}$ and that of the latter is $1 \quad p_{0}$. We can think of a Tullock's contest with two competitors: one is the alliance of countries A and B, the other is an opposing alliance. The effort of the former is $M_{1}$ and that of the latter is 
fixed at $\left(1 / p_{0} p_{d}\right)$. Eq.(18) means that even if the alliance of A and B loses the Tullock's contest, the alliance becomes a good state with probability $p_{0}$. In this paper, however, the bad state is not necessarily the loss of this kind of contest. Thus, we write the loss reduction function as in (18).

${ }^{8}$ If we treat national security as a whole with no disaggregation into self-insurance and self-protection (as in the conventional framework of public good provision) a decrease in the threat from an enemy reduces contribution (as a \% of GDP), where the decline in the percent contribution of the smaller country is greater than that of the larger country. This outcome is consistent with the exploitation hypothesis. But we cannot explain the change of security outlays in 1990s by using this model. Thus, if the loss in bad state increases, the conventional framework of single public good is inadequate.

${ }^{9}$ One could argue that the big country will move first as a Stackelberg-leader. In other calculations (available on request) we considered a leader-follower model with country A the leader and B the follower. It turned out that those results of simulated NATO burden sharing were less consistent with the actual burden sharing history than the results reported here. 


\section{REFERENCES}

Cornes, R., and Itaya, J. (2010) " On the Private Provision of Two or More Public Goods," Journal of Public Economic Theory, 12(2), 363-385.

Cornes, R. and T. Sandler (1984) Easy riders, joint production and public goods, Economic Journal 94, 580-598.

Cornes, R. and T. Sandler (1994) The comparative static properties of the impure public good model, Journal of Public Economics, 54:403-421.

Ehrlich, I. and G. Becker (1972) Market insurance, self-insurance, and self-protection, Journal of Political Economy 80: 623-648.

Hirshleifer, J. (1989) Conflict and rent-seeking success functions: Ratio vs. difference models of relative success, Public Choice 63, 101-112.

Ihori, T. and M. C. McGuire (2007), Collective risk control and group security: The unexpected consequences of differential risk aversion, Journal of Public Economic Theory, 9, 231-263.

IIhori, T. and M. C. McGuire (2010), National self-insurance and self-protection against adversity: Bureaucratic management of security and moral hazard. Economics of Governance, 11, 231-263.

Ihori, T., M. C. McGuire, and S. Nakagawa (2011), International Security, Insurance, and Protection: Failure of the Conventional Model of Alliances, mimeo.

Kerschbamer, R. and C. Puppe (1998), Voluntary Contributions when the Public Good Is not Necessarily Normal, Journal of Economics 68, 175-192.

Murdoch, J. C. and T. Sandler (1984) Complementarity, free riding, and the military expenditures of NATO allies, Journal of Public Economics 25, 83-101.

Olson, M. and R. Zeckhauser (1966) An Economic Theory of Alliances, Review of Economics and Statistics 48, 266-279.

Oneal, J. R. and P. F. Diehl (1994) The Theory of Collective Action and NATO Defense Burdens: New Empirical Tests, Political Research Quarterly 47, 373-396.

Sandler, T. (1992) Collective Action: The Theory and Application, Ann Arbor: Univ of MI Press

Sandler, T. (1997) Global Challenges: An approach to environmental, political, and economic problems. New York: Cambridge University Press.

Sandler, T. (2005) Collective versus unilateral responses to terrorism, Public Choice.

Sandler, T. and Forbes, J. F, (1980) Burden Sharing, Strategy, and the Design of NATO, Economic Inquiry, $18,425-44$.

Sandler, T. and K. Hartley (1995), The Economics of Defense, Cambridge UP

Sandler, T. and K. Hartley (2001), Economics of Alliances: The Lessons for Collective Action, Journal of Economic Literature,39, 869-896.

Sandler, T. and H. Shimizu (2012) NATO Burden Sharing 1999-2010: An Altered Alliance, Foreign Policy 
Analysis, forthcoming.

Schlesinger, H. (2000) The Theory of Insurance Demand, Ch 5 in Dionne ed., Handbook of Insurance, Kluwer,.

Tullock, G. (1967) The Welfare Costs of Tariffs, Monopolies, and Theft, Western Economic Journal 5, 224-232. 
Table 4.1(a): 5-year average of military expenditures as \% of GDPs (based on current prices)

\begin{tabular}{lccccccc}
\hline Country Name & $1975-$ & $1980-$ & $1985-$ & $1990-$ & $1995-$ & $2000-$ & $2005-$ \\
\hline Belgium & 1979 & 1984 & 1989 & 1994 & 1999 & 2004 & 2009 \\
Denmark & 3.2 & 3.2 & 2.8 & 1.9 & 1.5 & 1.3 & 1.2 \\
France & 2.4 & 2.4 & 2.0 & 1.9 & 1.7 & 1.5 & 1.4 \\
Germany & 3.8 & 4.0 & 3.8 & 3.3 & 2.9 & 2.5 & 2.3 \\
Greece & 3.4 & 3.3 & 3.0 & 2.1 & 1.6 & 1.4 & 1.3 \\
Italy & 5.6 & 5.3 & 5.1 & 3.9 & 4.1 & 3.2 & 2.8 \\
Luxembourg & 2.0 & 2.1 & 2.3 & 2.0 & 1.9 & 2.0 & 1.6 \\
Netherlands & 0.9 & 1.0 & 1.0 & 0.7 & 0.7 & 0.7 & 0.5 \\
Norway & 3.1 & 3.0 & 2.8 & 2.3 & 1.8 & 1.5 & 1.5 \\
Portugal & 2.9 & 2.7 & 2.9 & 2.8 & 2.2 & 1.9 & 1.5 \\
Turkey & 3.4 & 2.9 & 2.7 & 2.3 & 2.1 & 1.7 & 1.5 \\
United Kingdom & 4.4 & 4.0 & 3.3 & 2.8 & 3.2 & 3.2 & 2.0 \\
Canada & 4.9 & 5.2 & 4.5 & 3.7 & 2.7 & 2.3 & 2.5 \\
United States & 1.9 & 2.0 & 2.1 & 1.8 & 1.3 & 1.2 & 1.3 \\
\hline
\end{tabular}

Sources: North Atlantic Treaty Organization (1996, 2000, 2011) "Financial and Economic Data Relating to NATO defense" Table 3, < http://www.nato.int/cps/en/natolive/index.htm >

Table 4.1(b): 5-year average of national GDP as \% of the total GDP of 14 member countries of NATO

\begin{tabular}{lrrrrrrr}
\multicolumn{7}{c}{ (based on constant 2000 US\$) } \\
\hline Country Name & $1975-$ & $1980-$ & $1985-$ & $1990-$ & $1995-$ & $2000-$ & $2005-$ \\
Belgium & 1979 & 1984 & 1989 & 1994 & 1999 & 2004 & 2009 \\
Denmark & 1.6 & 1.5 & 1.4 & 1.4 & 1.3 & 1.3 & 1.3 \\
France & 1.1 & 1.0 & 1.0 & 0.9 & 0.9 & 0.9 & 0.9 \\
Germany & 9.0 & 8.6 & 8.1 & 8.0 & 7.6 & 7.4 & 7.2 \\
Greece & 12.9 & 12.2 & 11.3 & 11.8 & 11.1 & 10.3 & 9.9 \\
Italy & 1.0 & 0.9 & 0.8 & 0.7 & 0.7 & 0.7 & 0.8 \\
Luxembourg & 7.5 & 7.3 & 7.0 & 6.9 & 6.4 & 6.1 & 5.7 \\
Netherlands & 0.1 & 0.1 & 0.1 & 0.1 & 0.1 & 0.1 & 0.1 \\
Norway & 2.4 & 2.2 & 2.1 & 2.1 & 2.1 & 2.1 & 2.1 \\
Portugal & 0.9 & 0.9 & 0.9 & 0.9 & 1.0 & 0.9 & 1.0 \\
Turkey & 0.6 & 0.6 & 0.6 & 0.7 & 0.6 & 0.6 & 0.6 \\
United Kingdom & 1.3 & 1.2 & 1.3 & 1.4 & 1.5 & 1.5 & 1.8 \\
Canada & 9.7 & 8.7 & 8.7 & 8.3 & 8.3 & 8.4 & 8.4 \\
United States & 4.3 & 4.1 & 4.1 & 3.9 & 4.0 & 4.1 & 4.2 \\
\hline
\end{tabular}

Sources: The World Bank (2011) "World Development Indicators \& Global Development Finance," 15 December, 2011, < http://data.worldbank.org/data-catalog/world-development-indicators > 
Table 4.2: Parameter values

\begin{tabular}{ccccc}
\hline & & $\bar{L}$ & $p_{0}$ & $p_{d}$ \\
\hline 0.9 & 0.9 & 10 & 0.25 & 1 \\
\hline
\end{tabular}

Table 4.3 Numerical simulations corresponding to burden sharing in NATO

\begin{tabular}{|c|c|c|c|c|}
\hline & 1 & 2 & 3 & 4 \\
\hline $1 Y^{A}$ & 40 & 50 & 60 & 60 \\
\hline $2 Y^{B}$ & 24 & 30 & 36 & 36 \\
\hline $3 \bar{L}^{A}$ & 10 & 10 & 15 & 10 \\
\hline $4 \bar{L}^{B}$ & 6 & 6 & 9 & 6 \\
\hline $5 m_{1}^{A}$ & 1.316 & 1.348 & 2.690 & 1.380 \\
\hline $6 m_{2}^{A}$ & 2.569 & 2.098 & 5.234 & 1.619 \\
\hline $7 m_{1}^{B}$ & 0.000 & 0.000 & 0.000 & 0.000 \\
\hline $8 m_{2}^{B}$ & 0.505 & 0.392 & 0.192 & 0.280 \\
\hline $9 p\left(M_{1}\right)$ & 0.436 & 0.439 & 0.552 & 0.442 \\
\hline $10 F\left(M_{2}\right)$ & 2.767 & 2.241 & 4.884 & 1.709 \\
\hline $11 C^{1 A}$ & 35.356 & 45.971 & 53.055 & 56.580 \\
\hline $12 C^{0 A}$ & 31.450 & 40.892 & 47.193 & 50.329 \\
\hline $13 C^{1 B}$ & 23.346 & 29.500 & 35.844 & 35.647 \\
\hline $14 C^{0 B}$ & 20.767 & 26.241 & 31.884 & 31.709 \\
\hline $15 W^{A}$ & 14.190 & 14.568 & 14.798 & 14.874 \\
\hline $16 W^{B}$ & 13.613 & 13.936 & 14.229 & 14.203 \\
\hline $17 Y^{A}+m_{1}^{B}+m_{2}^{B}$ & 40.654 & 50.500 & 60.156 & 60.353 \\
\hline $18 Y^{B}+m_{1}^{A}+m_{2}^{A}$ & 28.644 & 34.029 & 42.945 & 39.420 \\
\hline $19\left(m_{1}^{A}+m_{2}^{A}\right) / Y^{A}$ & $11.609 \%$ & $8.058 \%$ & $11.576 \%$ & $5.700 \%$ \\
\hline $20\left(m_{1}^{B}+m_{2}^{B}\right) / Y^{B}$ & $2.726 \%$ & $1.667 \%$ & $0.434 \%$ & $0.981 \%$ \\
\hline
\end{tabular}


Table A.1: Impact on Nash equilibrium of increase in A's income in two-country model

\begin{tabular}{|c|c|c|c|c|c|c|c|}
\hline & 1 & 2 & 3 & 4 & 5 & 6 & 7 \\
\hline $1 Y^{A}$ & 40 & 40 & 40 & 50 & 60 & 70 & 80 \\
\hline $2 Y^{B}$ & 40 & 40 & 40 & 40 & 40 & 40 & 40 \\
\hline $3 \bar{L}^{A}$ & 10 & 10 & 10 & 10 & 10 & 10 & 10 \\
\hline $4 \bar{L}^{B}$ & 10 & 10 & 10 & 10 & 10 & 10 & 10 \\
\hline $5 m_{1}^{A}$ & 0.485 & 0.000 & 0.981 & 0.000 & 0.000 & 0.000 & 0.000 \\
\hline $6 m_{2}^{A}$ & 1.786 & 1.750 & 1.831 & 1.177 & 0.520 & 0.000 & 0.000 \\
\hline $7 m_{1}^{B}$ & 0.485 & 0.981 & 0.000 & 1.137 & 1.312 & 1.447 & 1.447 \\
\hline $8 m_{2}^{B}$ & 1.786 & 1.831 & 1.750 & 2.163 & 2.560 & 2.884 & 2.884 \\
\hline $9 p\left(M_{1}\right)$ & 0.396 & 0.398 & 0.398 & 0.416 & 0.435 & 0.449 & 0.449 \\
\hline $10 F\left(M_{2}\right)$ & 3.216 & 3.223 & 3.223 & 3.006 & 2.772 & 2.596 & 2.596 \\
\hline $11 C^{1 A}$ & 36.795 & 37.349 & 36.247 & 48.347 & 59.326 & 70.000 & 80.000 \\
\hline $12 C^{0 A}$ & 32.730 & 33.223 & 32.242 & 43.006 & 52.772 & 62.596 & 72.596 \\
\hline $13 C^{1 B}$ & 36.795 & 36.247 & 37.349 & 35.827 & 35.366 & 35.017 & 35.017 \\
\hline $14 C^{0 B}$ & 32.730 & 32.242 & 33.223 & 31.869 & 31.459 & 31.149 & 31.149 \\
\hline $15 W^{A}$ & 14.240 & 14.262 & 14.219 & 14.638 & 14.944 & 15.200 & 15.417 \\
\hline $16 W^{B}$ & 14.240 & 14.219 & 14.262 & 14.206 & 14.190 & 14.179 & 14.179 \\
\hline $17 Y^{A}+m_{1}^{B}+m_{2}^{B}$ & 43.205 & 43.753 & 42.651 & 54.173 & 64.634 & 74.983 & 84.983 \\
\hline $18 Y^{B}+m_{1}^{A}+m_{2}^{A}$ & 43.205 & 42.651 & 43.753 & 41.653 & 40.674 & 40.000 & 40.000 \\
\hline
\end{tabular}


Table A.2: Impact of increasing income combined with loss in the bad state: two-country model

\begin{tabular}{|c|c|c|c|c|c|c|c|}
\hline & 1 & 2 & 3 & 4 & 5 & 6 & 7 \\
\hline $1 Y^{A}$ & 40 & 40 & 40 & 50 & 60 & 70 & 80 \\
\hline $2 Y^{B}$ & 40 & 40 & 40 & 40 & 40 & 40 & 40 \\
\hline $3 \bar{L}^{A}$ & 10 & 10 & 10 & 15 & 20 & 25 & 30 \\
\hline $4 \bar{L}^{B}$ & 10 & 10 & 10 & 10 & 10 & 10 & 10 \\
\hline $5 m_{1}^{A}$ & 0.485 & 0.000 & 0.981 & 2.704 & 3.819 & 4.777 & 5.643 \\
\hline $6 m_{2}^{A}$ & 1.786 & 1.750 & 1.831 & 5.956 & 9.488 & 13.065 & 16.736 \\
\hline $7 m_{1}^{B}$ & 0.485 & 0.981 & 0.000 & 0.000 & 0.000 & 0.000 & 0.000 \\
\hline $8 m_{2}^{B}$ & 1.786 & 1.831 & 1.750 & 0.136 & 0.000 & 0.000 & 0.000 \\
\hline $9 p\left(M_{1}\right)$ & 0.396 & 0.398 & 0.398 & 0.552 & 0.616 & 0.658 & 0.689 \\
\hline $10 F\left(M_{2}\right)$ & 3.216 & 3.223 & 3.223 & 5.483 & 8.539 & 11.759 & 15.063 \\
\hline $11 C^{1 A}$ & 36.795 & 37.349 & 36.247 & 42.472 & 50.274 & 58.438 & 66.799 \\
\hline $12 C^{0 A}$ & 32.730 & 33.223 & 32.242 & 37.779 & 44.720 & 51.982 & 59.419 \\
\hline $13 C^{1 B}$ & 36.795 & 36.247 & 37.349 & 39.890 & 40.000 & 40.000 & 40.000 \\
\hline $14 C^{0 B}$ & 32.730 & 32.242 & 33.223 & 35.483 & 38.539 & 41.759 & 45.063 \\
\hline $15 W^{A}$ & 14.240 & 14.262 & 14.219 & 14.472 & 14.730 & 14.960 & 15.167 \\
\hline $16 W^{B}$ & 14.240 & 14.219 & 14.262 & 14.382 & 14.441 & 14.483 & 14.515 \\
\hline $17 Y^{A}+m_{1}^{B}+m_{2}^{B}$ & 43.205 & 43.753 & 42.651 & 50.110 & 60.000 & 70.000 & 80.000 \\
\hline $18 Y^{B}+m_{1}^{A}+m_{2}^{A}$ & 43.205 & 42.651 & 43.753 & 47.528 & 49.726 & 51.562 & 53.201 \\
\hline
\end{tabular}


Table A.3: Asymmetric two-country model: impact of a smaller loss in the bad state

\begin{tabular}{|c|c|c|c|c|c|c|c|}
\hline & 1 & 2 & 3 & 4 & 5 & 6 & 7 \\
\hline $1 Y^{A}$ & 50 & 50 & 50 & 50 & 50 & 50 & 50 \\
\hline $2 Y^{B}$ & 30 & 30 & 30 & 30 & 30 & 30 & 30 \\
\hline $3 \bar{L}^{A}$ & 21 & 16 & 11 & 10 & 9 & 8 & 7 \\
\hline $4 \bar{L}^{B}$ & 12.6 & 9.6 & 6.6 & 6 & 5.4 & 4.8 & 4.2 \\
\hline $5 m_{1}^{A}$ & 4.022 & 2.939 & 1.623 & 1.348 & 1.068 & 0.781 & 0.483 \\
\hline $6 m_{2}^{A}$ & 11.123 & 6.781 & 2.751 & 2.098 & 1.504 & 0.973 & 0.514 \\
\hline $7 m_{1}^{B}$ & 0.000 & 0.000 & 0.000 & 0.000 & 0.000 & 0.000 & 0.000 \\
\hline $8 m_{2}^{B}$ & 0.000 & 0.116 & 0.422 & 0.392 & 0.334 & 0.254 & 0.157 \\
\hline $9 p\left(M_{1}\right)$ & 0.626 & 0.568 & 0.466 & 0.439 & 0.408 & 0.372 & 0.331 \\
\hline $10 F\left(M_{2}\right)$ & 10.011 & 6.207 & 2.856 & 2.241 & 1.654 & 1.105 & 0.604 \\
\hline $11 C^{1 A}$ & 39.334 & 41.897 & 45.230 & 45.971 & 46.751 & 47.580 & 48.476 \\
\hline $12 C^{0 A}$ & 34.988 & 37.268 & 40.234 & 40.892 & 41.586 & 42.324 & 43.121 \\
\hline $13 C^{1 B}$ & 30.000 & 29.912 & 29.517 & 29.500 & 29.515 & 29.571 & 29.683 \\
\hline $14 C^{0 B}$ & 27.411 & 26.607 & 26.256 & 26.241 & 26.254 & 26.305 & 26.404 \\
\hline $15 W^{A}$ & 14.374 & 14.455 & 14.549 & 14.568 & 14.587 & 14.607 & 14.627 \\
\hline $16 W^{B}$ & 14.004 & 13.976 & 13.941 & 13.936 & 13.932 & 13.928 & 13.927 \\
\hline $17 Y^{A}+m_{1}^{B}+m_{2}^{B}$ & 50.000 & 50.088 & 50.483 & 50.500 & 50.485 & 50.429 & 50.317 \\
\hline $18 Y^{B}+m_{1}^{A}+m_{2}^{A}$ & 40.666 & 38.103 & 34.770 & 34.029 & 33.249 & 32.420 & 31.524 \\
\hline
\end{tabular}

